Nitrogen ion implantation on the mechanical properties of AISI 420 martensitic stainless steel

Jingfeng Zhang, Shixiang Peng, Jiamei Wen, Tao Zhang, Yuan Xu, Sha Yan, Haitao Ren State Key Laboratory of Nuclear Physics and Technology \& Institute of Heavy Ion Physics, Peking University

Ailin Zhang

University of Chinese Academy of Sciences 


\title{
Nitrogen ion implantation on the mechanical properties of AISI 420 martensitic
}

stainless steel

Jingfeng Zhang ${ }^{\mathrm{a}}$, Shixiang Peng ${ }^{\mathrm{a},{ }^{*}}$, Ailin Zhang ${ }^{\mathrm{b}}$, Jiamei Wen ${ }^{\mathrm{a}}$, Tao Zhang ${ }^{\mathrm{a}}$, Yuan Xu ${ }^{\mathrm{a}}$, Sha

$$
\text { Yan }^{\mathrm{a}}, \text { Haitao Ren }{ }^{\mathrm{a}}
$$

${ }^{a}$ State Key Laboratory of Nuclear Physics and Technology \& Institute of Heavy Ion Physics,

Peking University, Beijing 100871, China

${ }^{b}$ University of Chinese Academy of Sciences, Beijing 100049, China

\begin{abstract}
Nitrogen ions with different energy of $30 \mathrm{keV}$ and $50 \mathrm{keV}$ and dose of $5 \times 10^{16}, 5 \times 10^{17}$ and $1 \times 10^{18} \mathrm{~cm}^{-2}$ were implanted into the surface of AISI 420 martensitic stainless steel. The micro topography, roughness, friction coefficient, wear loss, hardness, as well as the chemical composition were investigated. Mounds and craters were found on the ion implanted surfaces, indicating increases in the roughness. However, very little changes in friction coefficient were detected after implantation. Nitrogen ions implantation on AISI 420 significantly improved the nanohardness, and the value of $16.2 \mathrm{GPa}$ at the depth of $17.3 \mathrm{~nm}$ was about 2.3 times as hard as the untreated samples at the same depth when the implant energy and dose were 50 $\mathrm{keV}$ and $5 \times 10^{16} \mathrm{~cm}^{-2}$, respectively. The wear loss of the implanted samples was less than that of untreated ones, and an optional dose of $5 \times 10^{17} \mathrm{~cm}^{-2}$ could be used for the wear resistance improvement. XPS results demonstrated that chromium nitrides were produced during ion implantation, which possibly contributes to the improvements of the hardness and wear resistance. The $\mathrm{N}$ 1s core spectra showed that nitrogen oxides was found in the samples with higher implantation dose, which had counteraction for the improvements of the hardness.
\end{abstract}




\section{Keywords}

AISI 420 martensitic stainless steel; Nitrogen ion implantation; Implantation energy; Implantation dose; Surface modification; Mechanical properties

\section{Introduction}

Ion implantation is the process where foreign species with energy can be introduced into the near-surface regions of a material [1]. It serves as a versatile tool for surface modification of materials. Compared with coating process, it does not involve the additional layer on the surface of sample [2]. Ion implantation can modify the surfaces of materials to improve their mechanical properties such as hardness [3], friction coefficient [4], wear resistance [5] and fatigue resistance [6]. There are many factors which affect the final quality of treated surfaces. Among them, dose and energy are the main factors [7].

While many attempts have been made in the past few decades to modify the surfaces of mostly austenitic stainless steels to increase their surface hardness and in general improve their tribological properties [8], martensitic stainless steel didn't get attention until a set of treatment parameters that gave rise to a layer with very favorable friction and wear properties in a martensitic stainless steel had been observed in the course of a comprehensive study of ion-nitrided austenitic and martensitic stainless steels [9].

Martensitic stainless steels are widely used as molds for plastic injection and glass molding, cutlery knives and scissor blades, automotive components, surgical and dental instruments. Because the service life time of industrial parts essentially depends on the surface properties, surface optimization treatments are more and more regarded as an essential step for the optimization of martensitic stainless steel [10]. AISI 420 martensitic stainless steel is one of the most popular martensitic steels in industrial applications. With reasonable corrosion 
resistance, the hardness and wear resistance of AISI 420 need to be improved for further diversification of its application [11].

Few published works have been reported on surface modification of AISI 420 with ion implantation especially beam ion implantation [12]. And there is also little research on evaluation of the surface properties of AISI 420 with different implantation conditions which include energy and dose. In this study, nitrogen ions with different energy and dose were implanted into the surface of AISI 420 martensitic stainless steel. And the improvements of surface mechanical properties are reported which provide a reference for the industrial applications.

\section{Materials and methods}

The samples used in this work were AISI 420 martensitic stainless steel provided by Goodfellow Cambridge Ltd. with the following chemical compositions (wt.\%.): Fe 86.7, $\mathrm{Cr}$ 13, $\mathrm{C} \mathrm{0.3.} \mathrm{The} \mathrm{samples} \mathrm{were} \mathrm{prepared} \mathrm{in} \mathrm{disks} \mathrm{with} \mathrm{the} \mathrm{size} \mathrm{of} 10 \mathrm{~mm} \times 10 \mathrm{~mm} \times 1.5 \mathrm{~mm}$. Ground with SiC papers and polished with diamond pastes, the samples were ultrasonically cleaned with acetone and ethanol, and dried prior to ion implantation.

The implantation of $\mathrm{N}^{+}$was carried out on PKU (Peking University) ion source test bench. Fig. 1 shows the details of PKU ion source test bench, which is composed of $2.45 \mathrm{GHz}$ ECR (electron cyclotron resonance) ion source, an emittance measurement device and a target plate. Special bypass vacuum design associated with a valve cuts the sample changing period from 4 hours to 10 minutes. The parameters of ion implantation are shown in Table 1 . As we can see from Fig. 1, there is cooling water in the target plate which kept the temperature of samples nearly $30^{\circ} \mathrm{C}$ during ion implantation. To predict the range of $\mathrm{N}^{+}$in AISI 420 martensitic stainless steel, calculations using SRIM (Stopping and Range of Ions in Matter) 
code package were done [13].

The surface topography micrographs and roughness were tested by Agilent 5500 Atomic Force Microscope (AFM). The scanning area of AFM is $10 \mu \mathrm{m} \times 10 \mu \mathrm{m}$. The experimental data were analyzed by using a Gwyddion2.31 software.

The friction and wear behaviors of the samples in a ball-on-disc configuration were investigated under dry conditions on an UMT-2 friction and wear tester manufactured by Bruker Corporation. During the test, the AISI 420 martensitic stainless steel disc rotated against a $\mathrm{Si}_{3} \mathrm{~N}_{4}$ ball of $4 \mathrm{~mm}$ in diameter. A sliding speed of $200 \mathrm{r} / \mathrm{min}$ and a constant load of $5 \mathrm{~N}$ were used for the test. The track length was $5 \mathrm{~mm}$ and the duration of test was $1 \mathrm{~h}$. The wear loss was measured by using an analytical balance (Sartorius, ME36S) with an accuracy of $0.001 \mathrm{mg}$.

The hardness of the samples was measured using the quasi-continuous stiffness measurement module of the nanoindentor (Agilent, G200). The range of measurement was $500 \mathrm{~nm}$. An average of 20 single measurements was used to determine the hardness and the elastic modulus.

X-ray photoelectron spectroscopy (XPS) analysis was performed on an AXIS-Ultra instrument from Kratos Analytical to determine the chemical state of the surface. The excitation source was monochromatic $\mathrm{Al} \mathrm{K}_{\alpha}$ radiation $(\mathrm{h} v=1486.7 \mathrm{eV})$. The correction of the binding energy shifts due to surface charging was made by referring to the $\mathrm{C} 1 \mathrm{~s}$ line of adsorbed hydrocarbons $(284.5 \mathrm{eV})$. The measuring depth was less than $10 \mathrm{~nm}$.

\section{Results and discussion}

As shown in Fig. 2, the SRIM calculations show that the range of $30 \mathrm{keV}$ and $50 \mathrm{keV} \mathrm{N}^{+}$in AISI 420 martensitic stainless steel are about $40 \mathrm{~nm}$ and $60 \mathrm{~nm}$. 


\subsection{Micrographs}

The micrographs of samples treated by $\mathrm{N}^{+}$with the energy of $50 \mathrm{keV}$ and different dose are shown in Fig. 3. Nitrogen ion implantation leads to the production of mounds and craters on the surface of AISI 420. With the same implantation energy, the intensity of mounds and craters increases with the increase of dose. Similar results were found for the samples implanted with $30 \mathrm{keV} \mathrm{N}^{+}$ions. The variation of surface roughness has relationship with the intensity of mounds and craters.

\subsection{Roughness}

The roughness of samples implanted with $\mathrm{N}^{+}$at various energy and dose is presented in Fig. 4. In general, $\mathrm{N}^{+}$implantation makes the roughness of AISI 420 increase except for the situation of $50 \mathrm{keV}, 5 \times 10^{16} \mathrm{~cm}^{-2}$. Ion implantation is a process of energy deposition which produces defects in the surface. At the same implantation dose, the roughness produced by 30 $\mathrm{keV} \mathrm{N}{ }^{+}$is larger than by $50 \mathrm{keV} \mathrm{N}$. The implantation with $50 \mathrm{keV} \mathrm{N}^{+}$may produce an effect like anneal which can recover the defects in some degree. The roughness increases with the increase of dose with the same implantation energy. The time of implantation is proportional to the dose. The implantation time of samples implanted with $50 \mathrm{keV}, 5 \times 10^{16} \mathrm{~cm}^{-2} \mathrm{~N}^{+}$was about ten minutes. And there was an instantaneous energy deposition which partially repaired the defects of the outermost surface for the short implantation time. The short-time effect may be the reason why the roughness of samples implanted with $50 \mathrm{keV}, 5 \times 10^{16} \mathrm{~cm}^{-2} \mathrm{~N}^{+}$is lower than that of untreated ones. Higher dose corresponds to longer implantation time which can produce more defects and larger roughness. The change of roughness with the dose agrees well with the phenomena observed in Fig. 3.

\subsection{Surface chemical station}


Fig. 5 (a) and (b) are the Fe 2p spectra of nitrogen implanted samples corresponding to the conditions of $30 \mathrm{keV}, 5 \times 10^{17} \mathrm{~cm}^{-2}$ and $50 \mathrm{keV}, 5 \times 10^{17} \mathrm{~cm}^{-2}$ respectively. The results analyzed by the $\mathrm{Fe} 2 \mathrm{p}$ spectra show that the iron is mainly in the form of iron oxides before and after nitrogen ion implantation.

Fig. 6 (a) and (b) are the Cr 2p spectra of nitrogen implanted samples corresponding to the conditions of $30 \mathrm{keV}, 5 \times 10^{17} \mathrm{~cm}^{-2}$ and $50 \mathrm{keV}, 5 \times 10^{17} \mathrm{~cm}^{-2}$ respectively. The compounds with the binding energy of $576.21 \mathrm{eV}$ are chromium nitrides and other peaks in the spectra should be the chromium oxides. The implanted nitrogen ions mainly react with chromium which is similar to the results got by Oñate et al [12]. Most elemental chromium has been converted into chromium nitrides and the relative content of chromium oxides is low.

Fig. 7 shows the $\mathrm{N}$ 1s spectra of nitrogen implanted samples corresponding to the conditions of $30 \mathrm{keV}, 5 \times 10^{16} \mathrm{~cm}^{-2}, 50 \mathrm{keV}, 5 \times 10^{16} \mathrm{~cm}^{-2}, 30 \mathrm{keV}, 5 \times 10^{17} \mathrm{~cm}^{-2}$ and $50 \mathrm{keV}$, $5 \times 10^{17} \mathrm{~cm}^{-2}$ respectively. The binding energy from 396.09 to $396.30 \pm 0.2 \mathrm{eV}$ and from 397.77 to $398.92 \pm 0.2 \mathrm{eV}$ corresponds to the chromium nitrides. Compared with the spectra of samples implanted with the dose of $5 \times 10^{16} \mathrm{~cm}^{-2}$, there is an apparent peak at the position of $403.57 \mathrm{eV}$ when the implantation dose is $5 \times 10^{17} \mathrm{~cm}^{-2}$. As ion implantation is a process of energy deposition and the implantation time is proportional to dose, the peak around 403.57 $\mathrm{eV}$ which appears when the implantation dose is higher may correspond to higher oxidation state of nitrogen.

\subsection{Nanohardness}

Surface nanohardness values of untreated and nitrogen implanted samples at various energy and dose are shown in Fig. 8. Nitrogen implanted samples show higher surface hardness compared with the untreated samples except for the situation of $50 \mathrm{keV}, 1 \times 10^{18} \mathrm{~cm}^{-2}$ 
under the depth of about $25 \mathrm{~nm}$. The nanohardness values increase as the implantation dose decreases with the same implantation energy. In the case of the samples implanted with the energy of $50 \mathrm{keV}$ and dose of $5 \times 10^{16} \mathrm{~cm}^{-2}$, the nanohardness value at the depth of $17.3 \mathrm{~nm}$ is 16.2 GPa which is about 2.3 times as hard as the untreated samples at the same depth.

The XPS spectra have shown that implanted nitrogen ions react with chromium to produce chromium nitrides which are in the form of interstitial compounds. In addition, there will be point defects for the collisions of nitrogen ions and elements in the surface. Both the chromium nitrides and point defects contribute to the improvement of surface hardness. The degree of amorphization of the surface increases with the increase of implantation dose, which accounts for the nanohardness reduction at higher dose. What's more, samples implanted with higher dose can produce more defects which may change the microstructure of the surface and reduce the nanohardness. The nanohardness of samples implanted with the dose of $5 \times 10^{16} \mathrm{~cm}^{-2}$ is higher than that of other dose. Referring to the results of XPS spectra, the production of higher oxidation state of nitrogen has impeded the increase of nanohardness. Samples implanted with the energy of $50 \mathrm{keV}$ and dose of $1 \times 10^{18} \mathrm{~cm}^{-2}$ can produce a great many defects especially in the outermost surface for the higher energy and dose. The production of a large number of defects and higher oxidation state of nitrogen in the outermost surface make the nanohardness of samples implanted with the energy of $50 \mathrm{keV}$ and dose of $1 \times 10^{18} \mathrm{~cm}^{-2}$ lower than that of untreated ones under the depth of about $25 \mathrm{~nm}$. The nanohardness of the samples will not always increase with the decrease of implantation dose. And there should be a suitable range of dose. Because samples implanted with too lower dose can't produce sufficient chromium nitrides and point defects. The difference of nanohardness for implanted and untreated samples doesn't disappear until at the depth of 200 
$\mathrm{nm}$ which is beyond the range calculated by SRIM. The increase of the improvement range is caused by irradiation enhanced diffusion.

\subsection{Friction and wear loss}

The friction coefficient of samples implanted at various energy and dose is shown in Fig. 9. After one-hour ball-on-disc test, the surface friction coefficient of samples implanted with $\mathrm{N}^{+}$ is almost unchanged, no matter what the energy and dose are. Nitrogen ion implantation does not change the friction mechanism of the AISI 420 surface.

Fig. 10 shows the wear loss of samples implanted with $\mathrm{N}^{+}$at various energy and dose after one-hour ball-on-disc test. The wear loss of samples implanted with nitrogen ions is lower than that of untreated ones. The reason is that the formation of chromium nitrides affects the plasticity of the surface. It's notable that the wear loss of samples implanted with $50 \mathrm{keV}$, $5 \times 10^{16} \mathrm{~cm}^{-2} \mathrm{~N}^{+}$is higher than that of other implanted samples. However, the hardness of samples implanted with $50 \mathrm{keV}, 5 \times 10^{16} \mathrm{~cm}^{-2} \mathrm{~N}^{+}$is higher than that of other implanted samples. The reason is that samples implanted with $50 \mathrm{keV}, 5 \times 10^{16} \mathrm{~cm}^{-2} \mathrm{~N}^{+}$can produce fewer defects compared with other implanted samples and the implanted nitrogen ions mainly react with chromium to produce chromium nitrides which are in the form of interstitial compounds. Due to the excessive concentration of the interstitial compounds, the surface compressive stresses of samples implanted with $50 \mathrm{keV}, 5 \times 10^{16} \mathrm{~cm}^{-2} \mathrm{~N}^{+}$are lower and the fragility is higher in comparison with those of other implanted samples. With the same implantation energy, the samples implanted with the dose of $5 \times 10^{17} \mathrm{~cm}^{-2}$ have the lowest wear loss. This can be attributed to that more defects are produced in the samples implanted with dose of $5 \times 10^{17} \mathrm{~cm}^{-2}$ and the surface compressive stresses are higher compared with samples implanted with dose of $5 \times 10^{16} \mathrm{~cm}^{-2}$. When the implanted dose gets increased to 
$1 \times 10^{18} \mathrm{~cm}^{-2}$, a large number of defects are produced in the surface and the microstructure of the surface might have been changed. Therefore the wear loss of samples implanted with dose of $1 \times 10^{18} \mathrm{~cm}^{-2}$ is higher than that of samples implanted with dose of $5 \times 10^{17} \mathrm{~cm}^{-2}$.

\section{Conclusions}

Nitrogen ions at various energy and dose were implanted into the surface of AISI 420 martensitic stainless steel to improve the mechanical properties of surface. The roughness increases and has relationship with the energy and dose. The results of XPS show that the chromium nitrides are produced during nitrogen ion implantation. And there is higher oxidation state of nitrogen when the implantation dose is higher. The nanohardness of the surface is improved, and samples implanted with $50 \mathrm{keV}, 5 \times 10^{16} \mathrm{~cm}^{-2} \mathrm{~N}^{+}$have the highest nanohardness. Nitrogen ions implantation nearly doesn't affect the friction coefficient of the surface. The wear resistance is improved a lot, and the dose of $5 \times 10^{17} \mathrm{~cm}^{-2}$ is most favorable to the improvement of wear loss. To get better results, we will study the modification of AISI 420 martensitic stainless steel using other ions like carbon. The results will provide reference for the surface modification of AISI 420 martensitic stainless steel using ion implantation.

\section{Acknowledgement}

The authors gratefully acknowledge the National Magnetic Confinement Fusion Program (No. 2013GB109004) and National Science Foundation of China (grant no. 11575013) for financial support of this research work. 


\section{References}

[1] G. Dearnaley, Ion implantation, Nature 256 (1975) 701-705.

[2] S. N. Kadam, K. R. Jagdeo, M. R. Nair, Improvement of tribological properties of Ti6Al4V alloy by nitrogen ion implantation, Int. Refereed J. Eng. Sci. 3 (2014) 30-34.

[3] E. Hug, S. Thibault, D. Chateigner, L. Maunoury, Nitriding aluminum alloys by N-multicharged ions implantation: Correlation between surface strengthening and microstructure modifications, Surf. Coat. Technol. 206 (2012) 5028-5035.

[4] J. Jin, Y. Chen, K. Gao, X. Huang, The effect of ion implantation on tribology and hot rolling contact fatigue of Cr4Mo4Ni4V bearing steel, Appl. Surf. Sci. 305 (2014) 93-100.

[5] R. Figueroa, C. M. Abreu, M. J. Cristóbal, G. Pena, Effect of nitrogen and molybdenum ion implantation in the tribological behavior of AA7075 aluminum alloy, Wear 276 (2012) 53-60.

[6] R. G. Vardiman, R. A. Kant, The improvement of fatigue life in $\mathrm{Ti}-6 \mathrm{Al}-4 \mathrm{~V}$ by ion implantation, J. Appl. Phys. 53 (1982) 690-694.

[7] A. Belbah, A. Mkaddem, N. Ladaci, N. Mebarki, M. El Mansori, Low energy implantation to inhibit wear in $\mathrm{N}^{+}$ions implanted WC-Co composite, Mater. Des. 53 (2014) 202-208.

[8] I. Alphonsa, A. Chainani, P. M. Raole, B. Ganguli, P. I. John, A study of martensitic stainless steel AISI 420 modified using plasma nitriding, Surf. Coat. Technol. 150 (2002) 263-268.

[9] K. Marchev, C. V. Cooper, B. C. Giessen, Observation of a compound layer with very low friction coefficient in ion-nitrided martensitic 410 stainless steel, Surf. Coat. Technol. 99 (1998) 229-233.

[10] Y. Samih, G. Marcos, N. Stein, N. Allain, E. Fleury, C. Dong, T. Grosdidier, Microstructure modifications and associated hardness and corrosion improvements in the AISI 420 martensitic stainless steel treated by high current pulsed electron beam (HCPEB), Surf. Coat. Technol. 259 (2014) 737-745.

[11] A. Çetin, Z. Tek, A. Öztarhan, N. Artunç, A comparative study of single and duplex treatment of martensitic AISI 420 stainless steel using plasma nitriding and plasma nitriding-plus-nitrogen ion implantation techniques, Surf. Coat. Technol. 201 (2007) 8127-8130.

[12] J. I. Oñate, J. K. Dennis, S. Hamilton, Wear behaviour of nitrogen-implanted AISI 420 martensitic stainless steel, Surf. Coat. Technol. 42 (1990) 119-131. 
[13] J. F. Ziegler, J. P. Biersack, The stopping and range of ions in matter, in: D. Allan Bromley, Treatise on Heavy-Ion Science, Springer US, New York, 1985, pp. 93-129. 
Table 1

Ion implantation parameters.

\begin{tabular}{ccc}
\hline Energy $(\mathrm{keV})$ & Dose $\left(\mathrm{cm}^{-2}\right)$ & 1 \\
& $5 \times 10^{16}$ & 1 \\
30 & $5 \times 10^{17}$ & 1 \\
& $1 \times 10^{18}$ & 1 \\
50 & $5 \times 10^{16}$ & 1 \\
& $5 \times 10^{17}$ & 1 \\
\hline
\end{tabular}


Fig. 1 PKU ion source test bench.

Fig. 2 Content distribution of $30 \mathrm{keV}$ and $50 \mathrm{keV} \mathrm{N}{ }^{+}$implanted into the AISI 420, calculated with SRIM software (a: $30 \mathrm{keV}$; b: $50 \mathrm{keV}$ ).

Fig. 3 AFM images of samples implanted with $\mathrm{N}^{+}$(a: untreated; b: $50 \mathrm{keV}, 5 \times 10^{16} \mathrm{~cm}^{-2}$; c: 50 $\mathrm{keV}, 5 \times 10^{17} \mathrm{~cm}^{-2}$; $\left.\mathrm{d}: 50 \mathrm{keV}, 1 \times 10^{18} \mathrm{~cm}^{-2}\right)$.

Fig. 4 Roughness of the samples implanted with $\mathrm{N}^{+}$at various energy and dose. Bars show standard deviation ( $\mathrm{n}=3$ experiments).

Fig. 5 Fe 2p spectra of AISI 420 implanted with $\mathrm{N}^{+}$(a: $30 \mathrm{keV}, 5 \times 10^{17} \mathrm{~cm}^{-2}$; b: $50 \mathrm{keV}$, $\left.5 \times 10^{17} \mathrm{~cm}^{-2}\right)$.

Fig. 6 Cr 2p spectra of AISI 420 implanted with $\mathrm{N}^{+}$(a: $30 \mathrm{keV}, 5 \times 10^{17} \mathrm{~cm}^{-2}$; b: $50 \mathrm{keV}$, $\left.5 \times 10^{17} \mathrm{~cm}^{-2}\right)$.

Fig. $7 \mathrm{~N}$ 1s spectra of AISI 420 implanted with $\mathrm{N}^{+}$(a: $30 \mathrm{keV}, 5 \times 10^{16} \mathrm{~cm}^{-2}$; b: $50 \mathrm{keV}, 5 \times 10^{16}$ $\mathrm{cm}^{-2}$; $: 30 \mathrm{keV}, 5 \times 10^{17} \mathrm{~cm}^{-2}$; d: $\left.50 \mathrm{keV}, 5 \times 10^{17} \mathrm{~cm}^{-2}\right)$.

Fig. 8 Nanohardness of samples implanted with $\mathrm{N}^{+}$at various energy and dose (a: $30 \mathrm{keV}$; $\mathrm{b}$ : $50 \mathrm{keV}$ ). Bars show standard deviation ( $\mathrm{n}=20$ experiments).

Fig. 9 Friction coefficient of samples implanted with $\mathrm{N}^{+}$at various energy and dose (a: 30 $\mathrm{keV}$; b: $50 \mathrm{keV})$.

Fig. 10 Wear loss of samples implanted with $\mathrm{N}^{+}$at various energy and dose. Bars show standard deviation ( $\mathrm{n}=3$ experiments). 


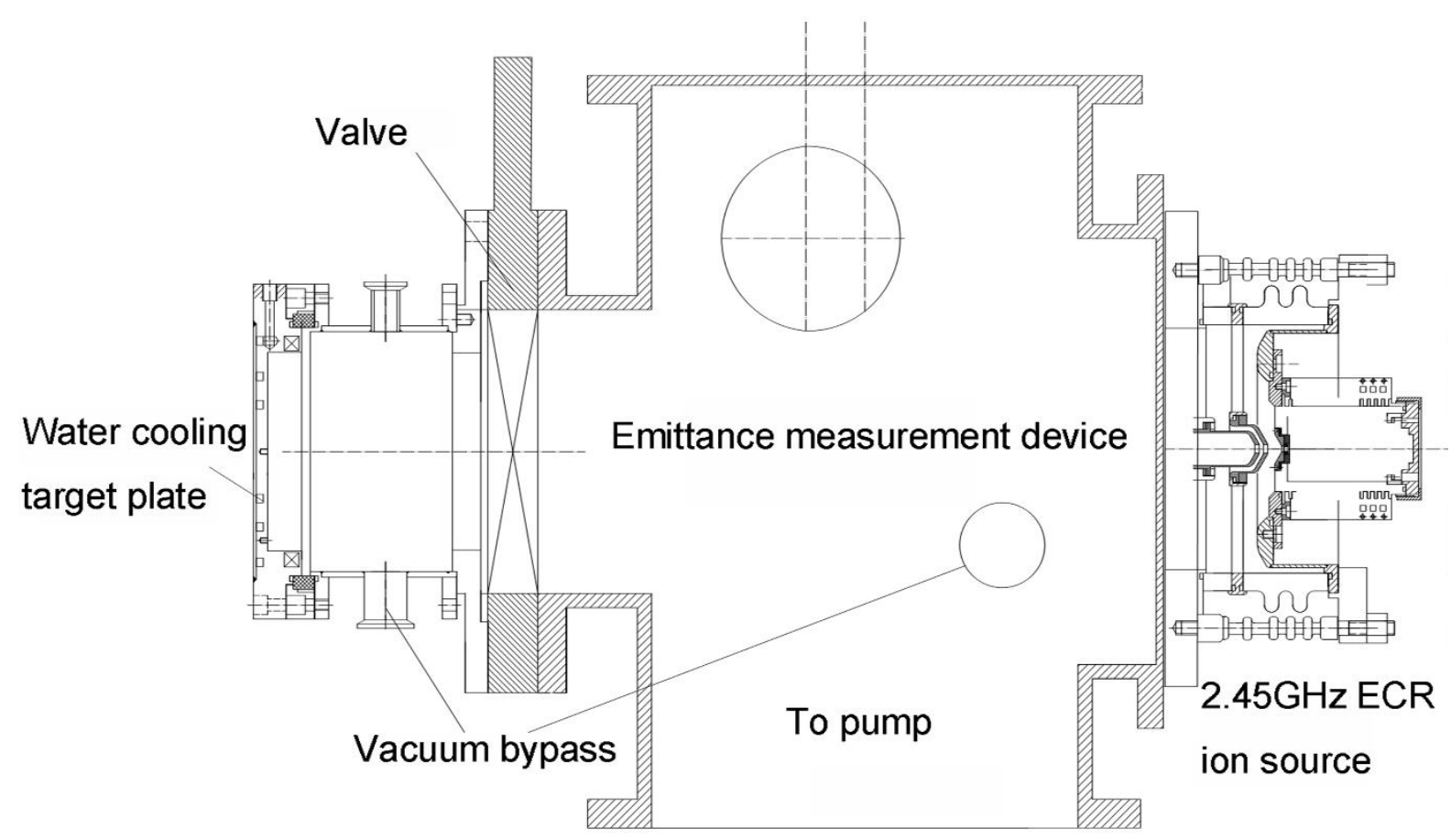

FIG 1

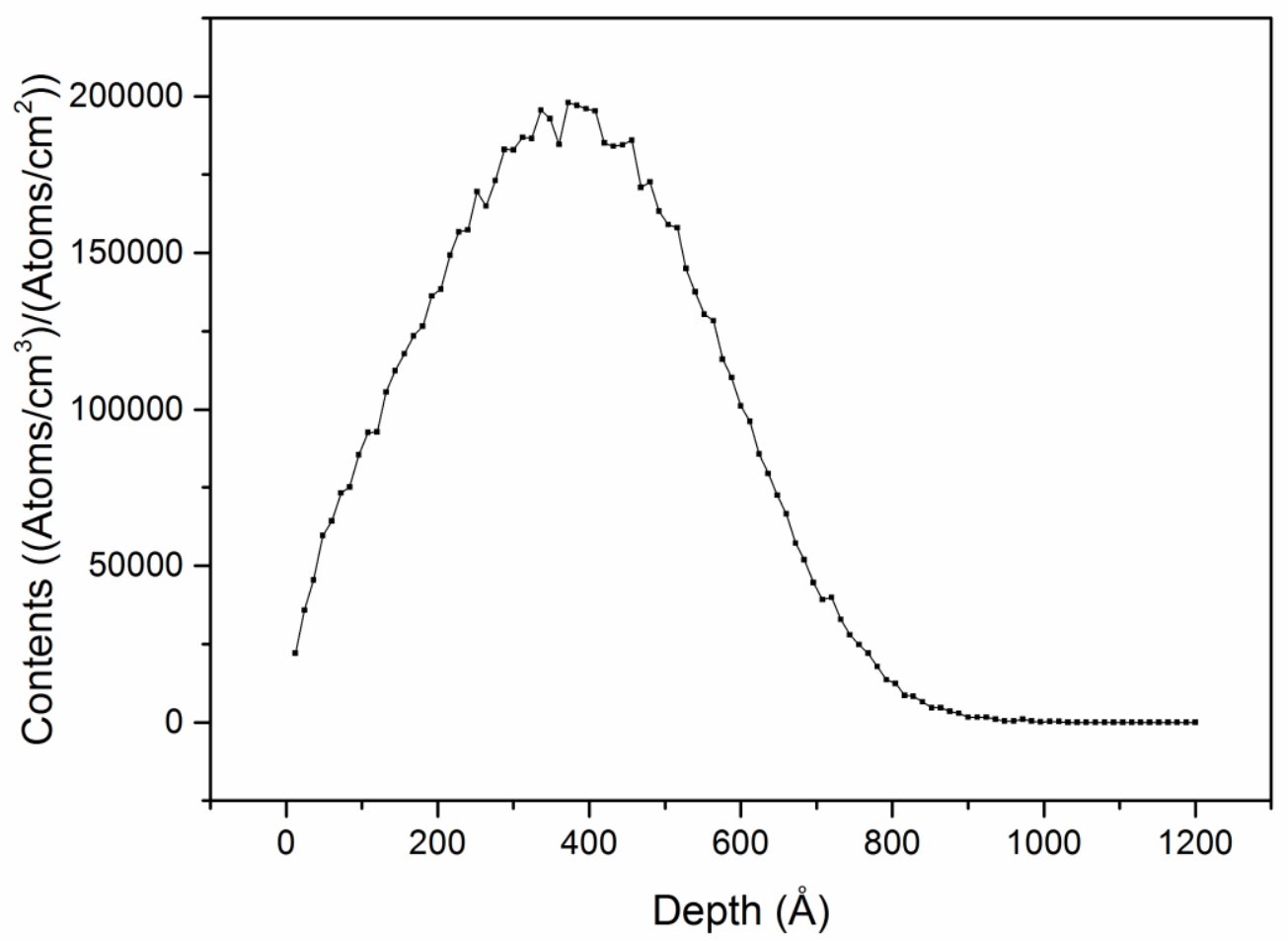

FIG 2a 


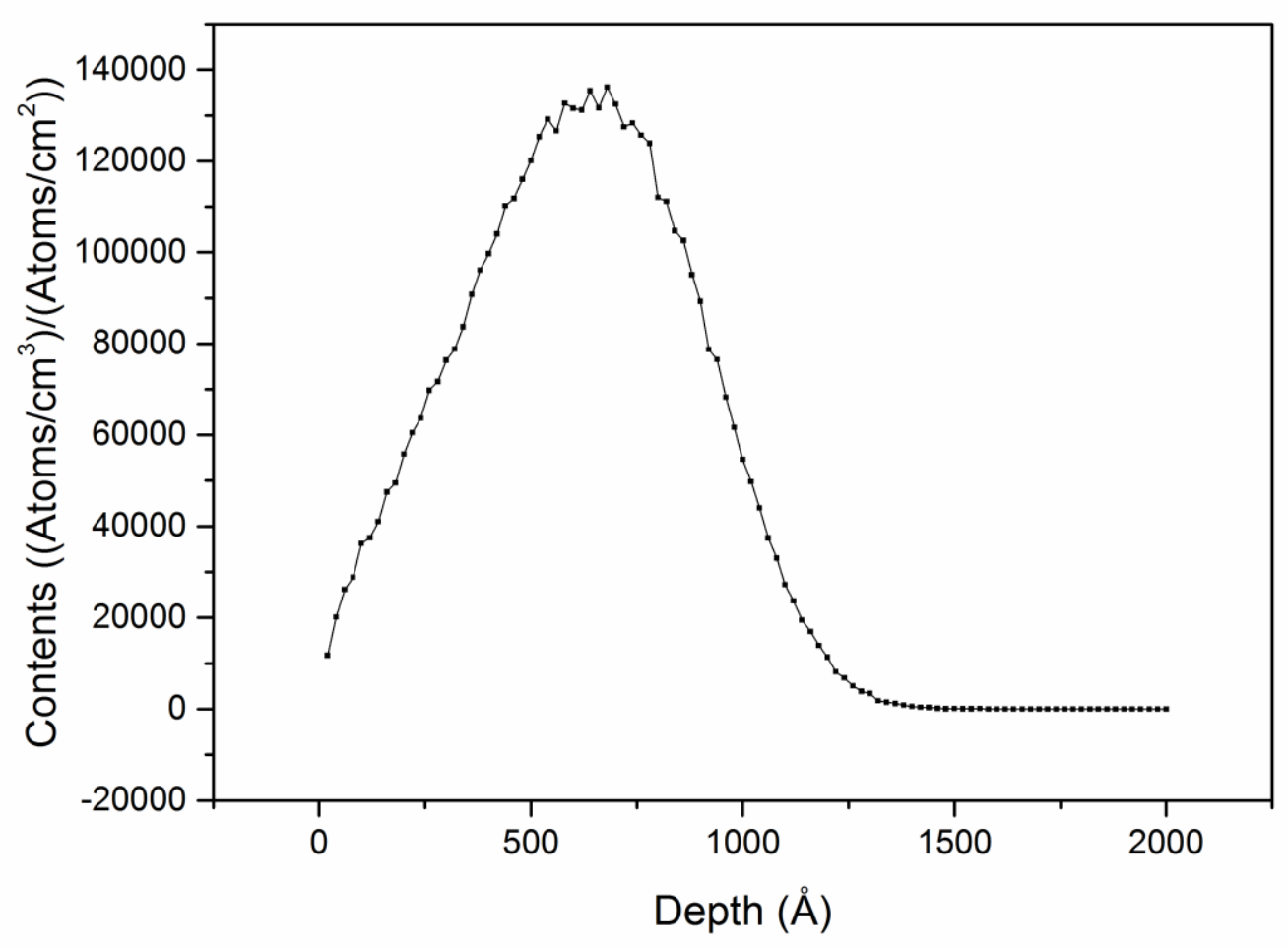

FIG 2b 


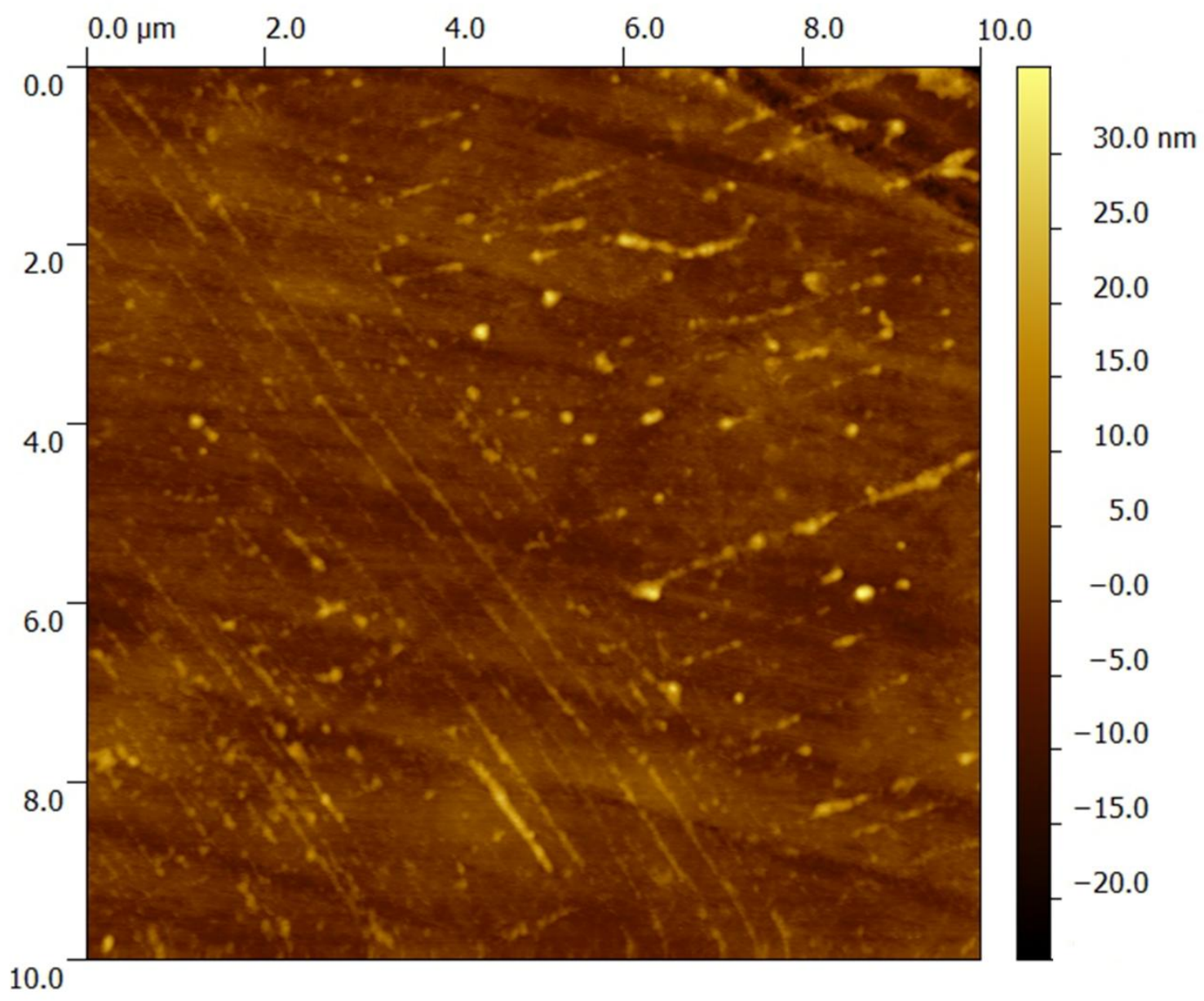

FIG 3a 


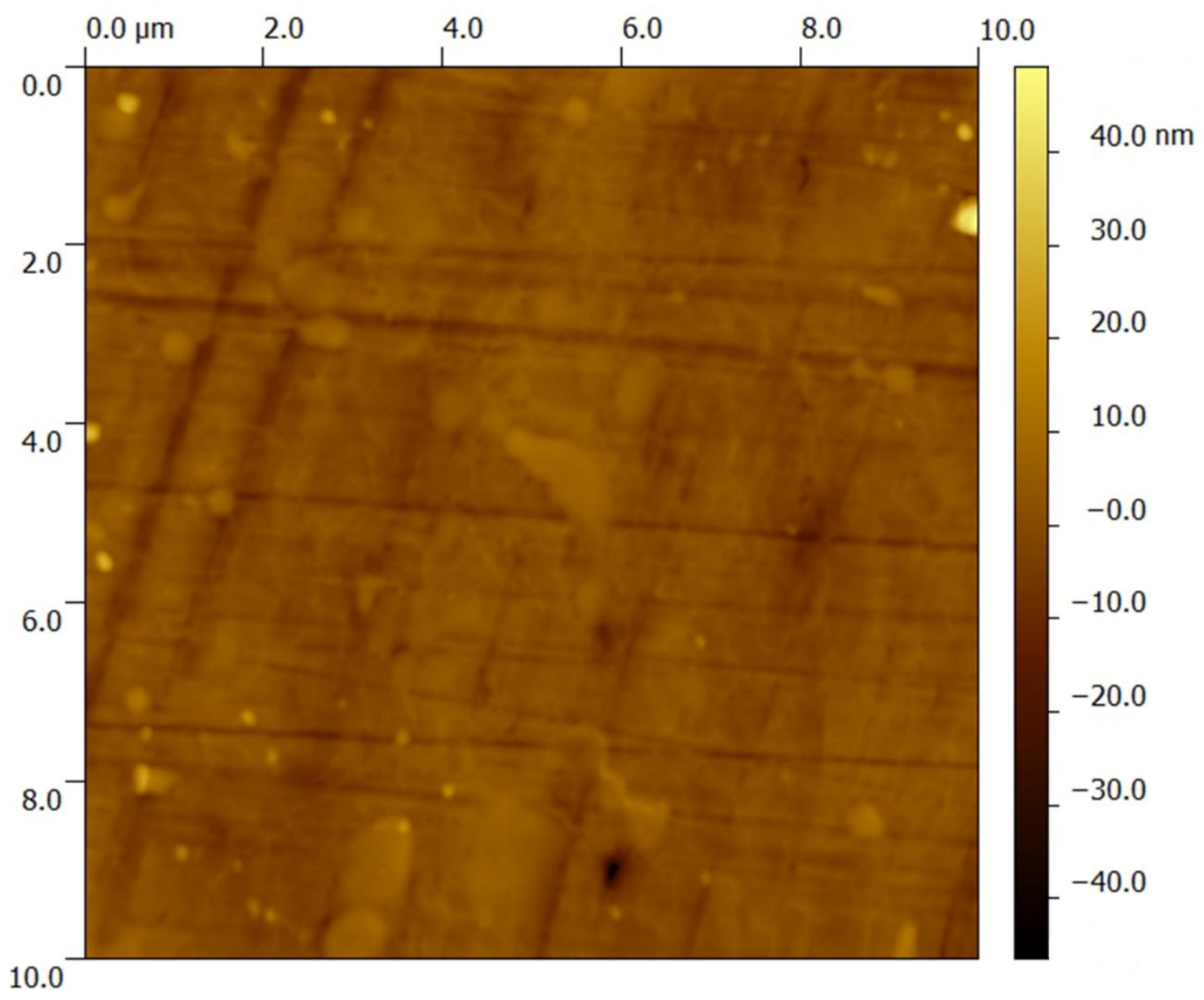

FIG 3b 


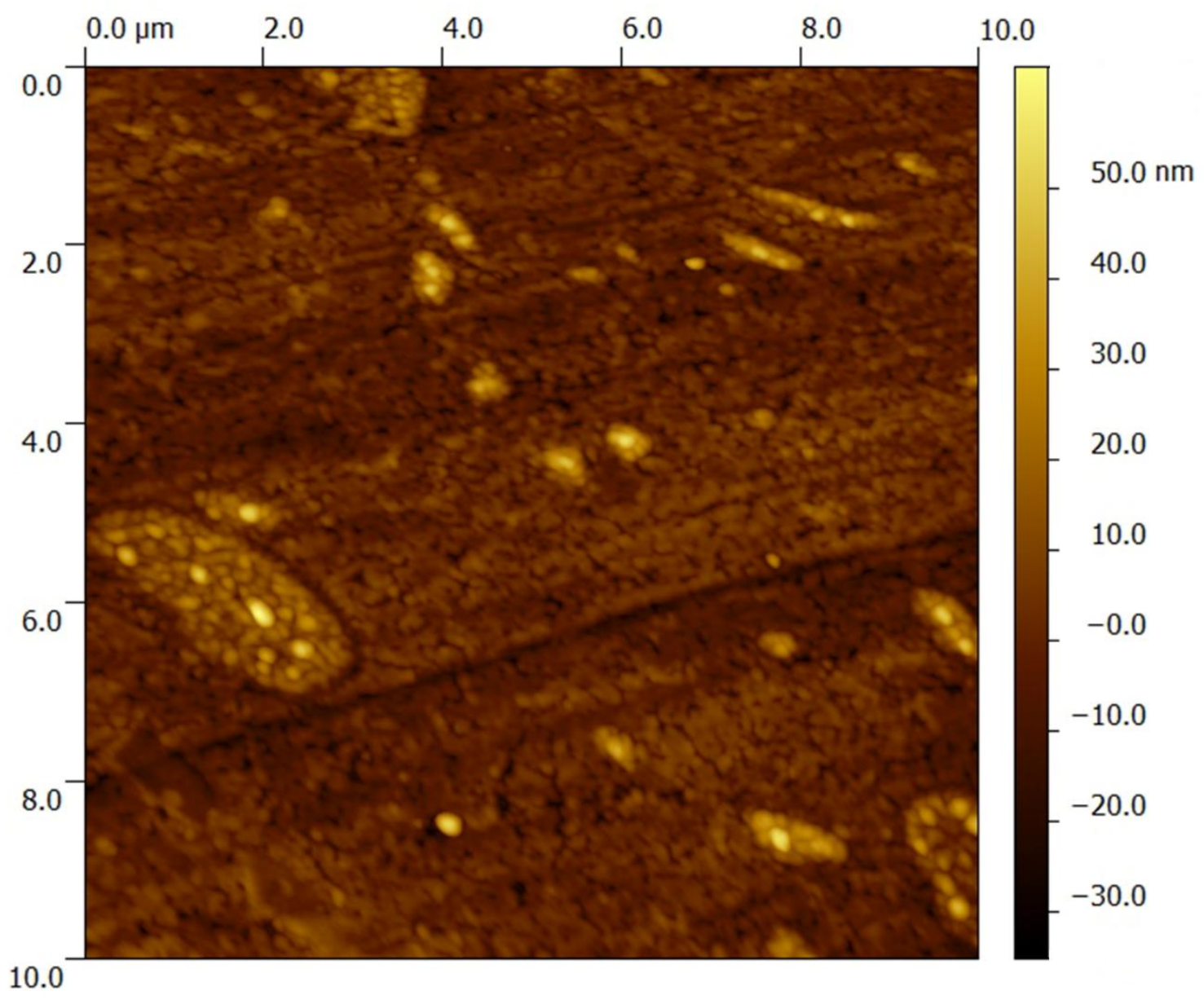

FIG 3c 


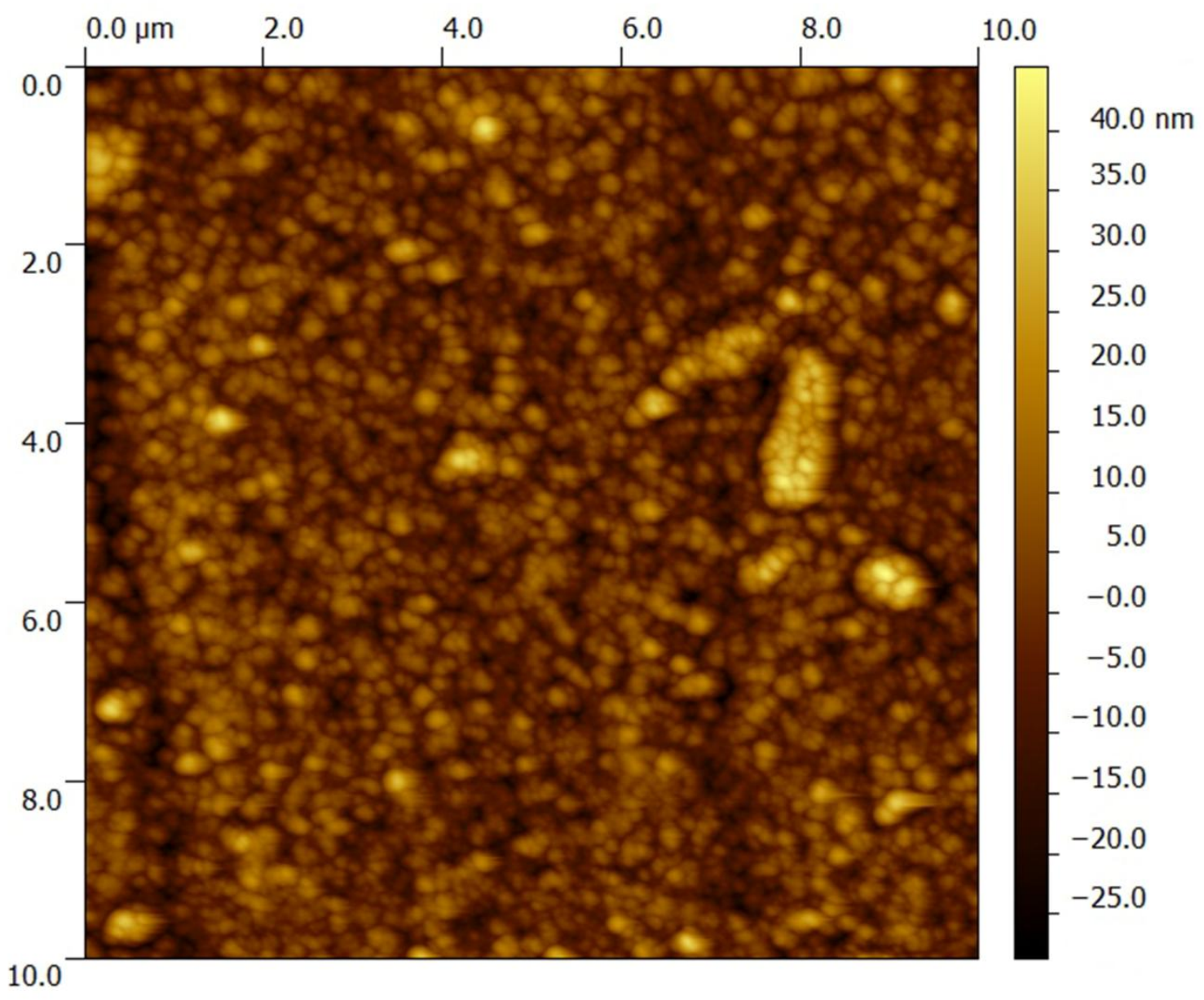

FIG 3d 


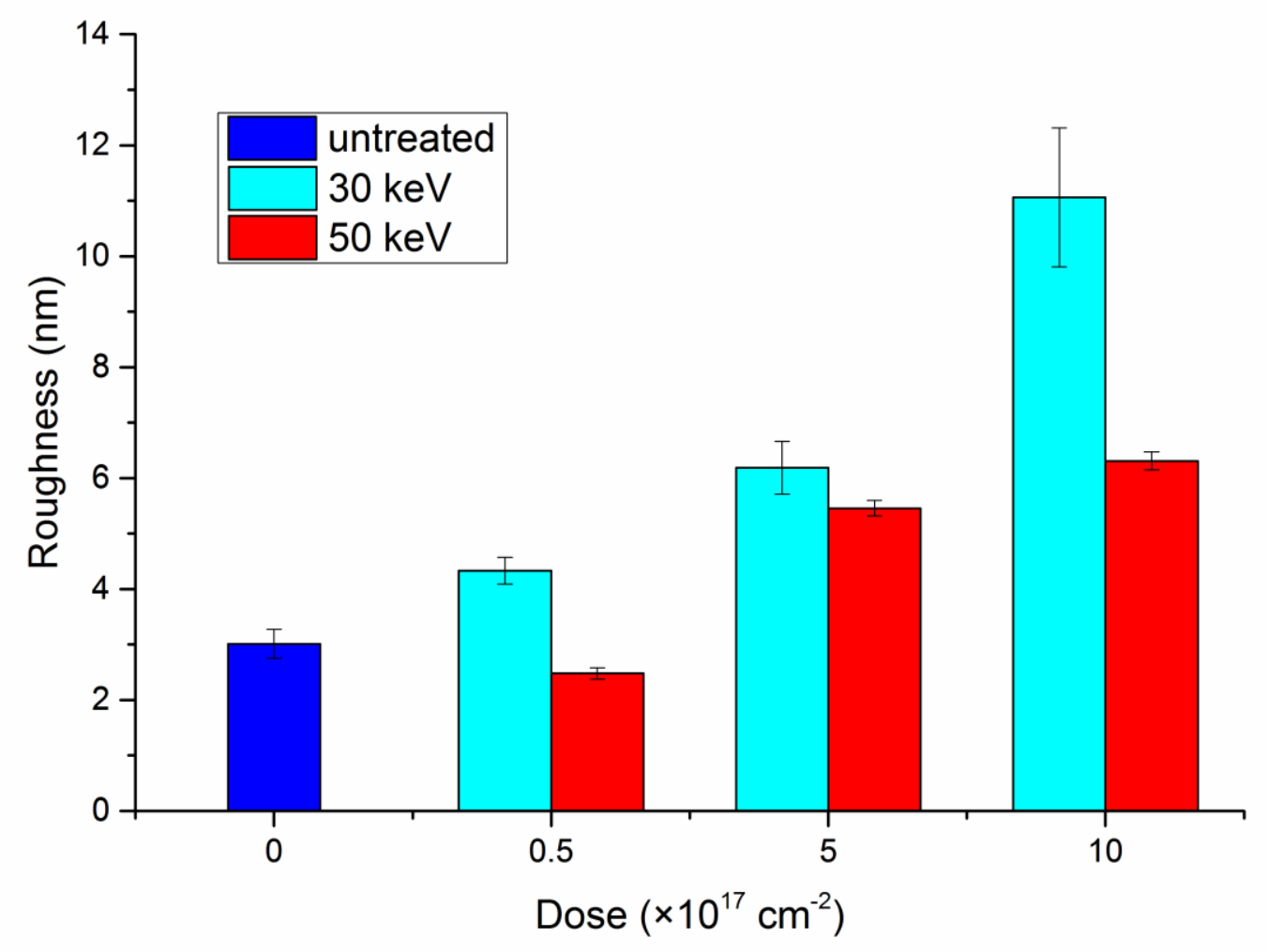

FIG 4

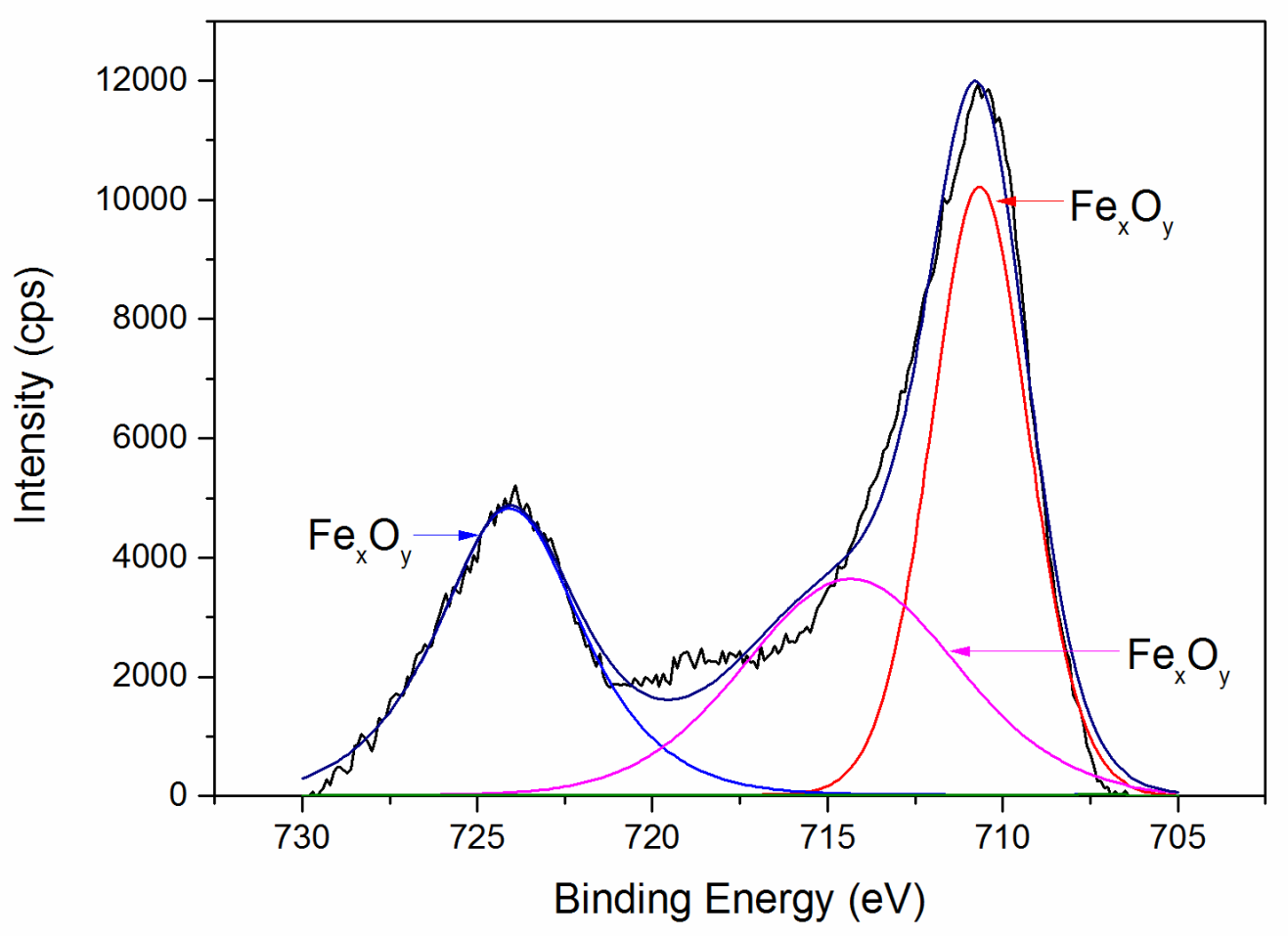

FIG 5a 


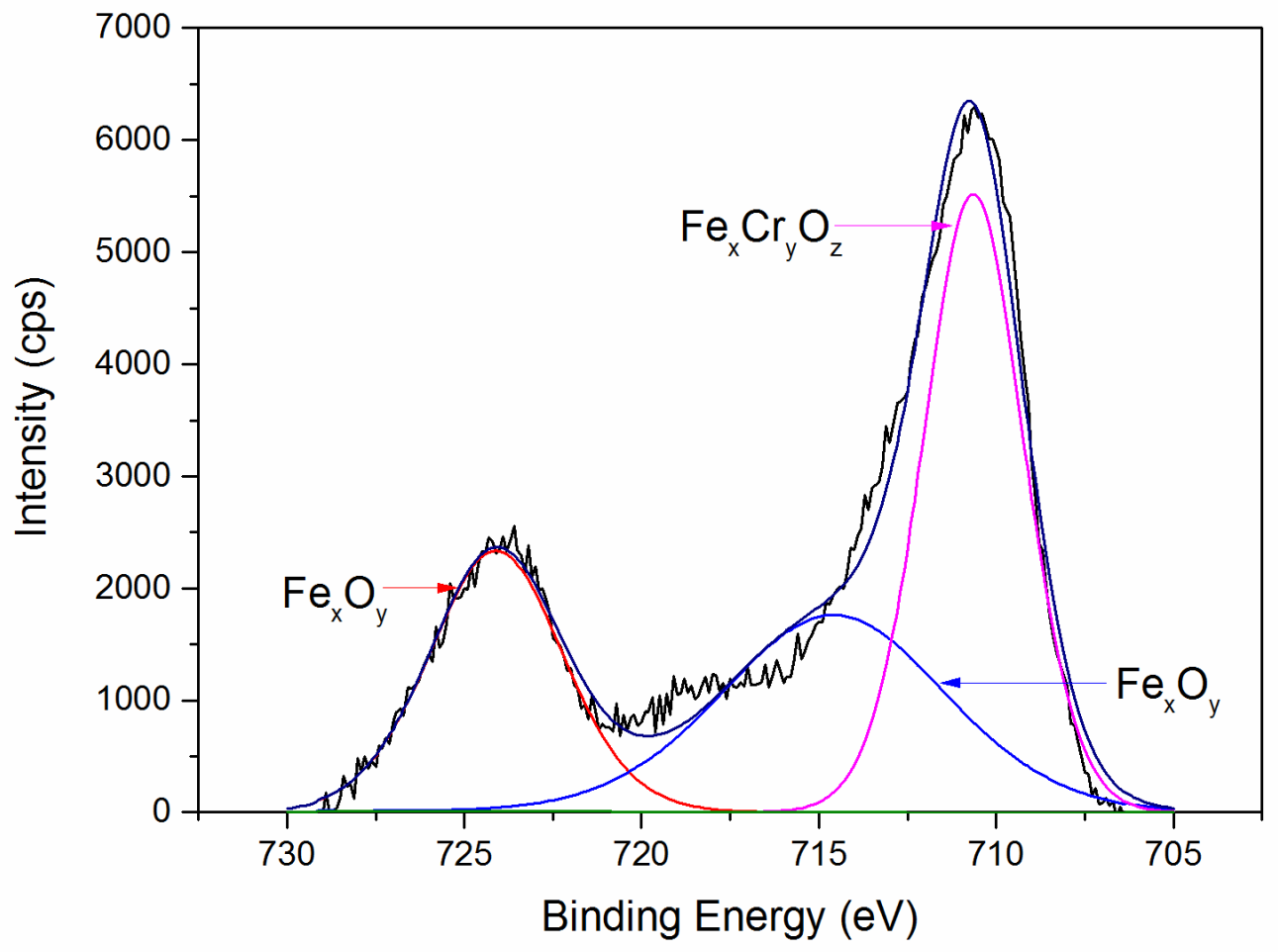

FIG 5b

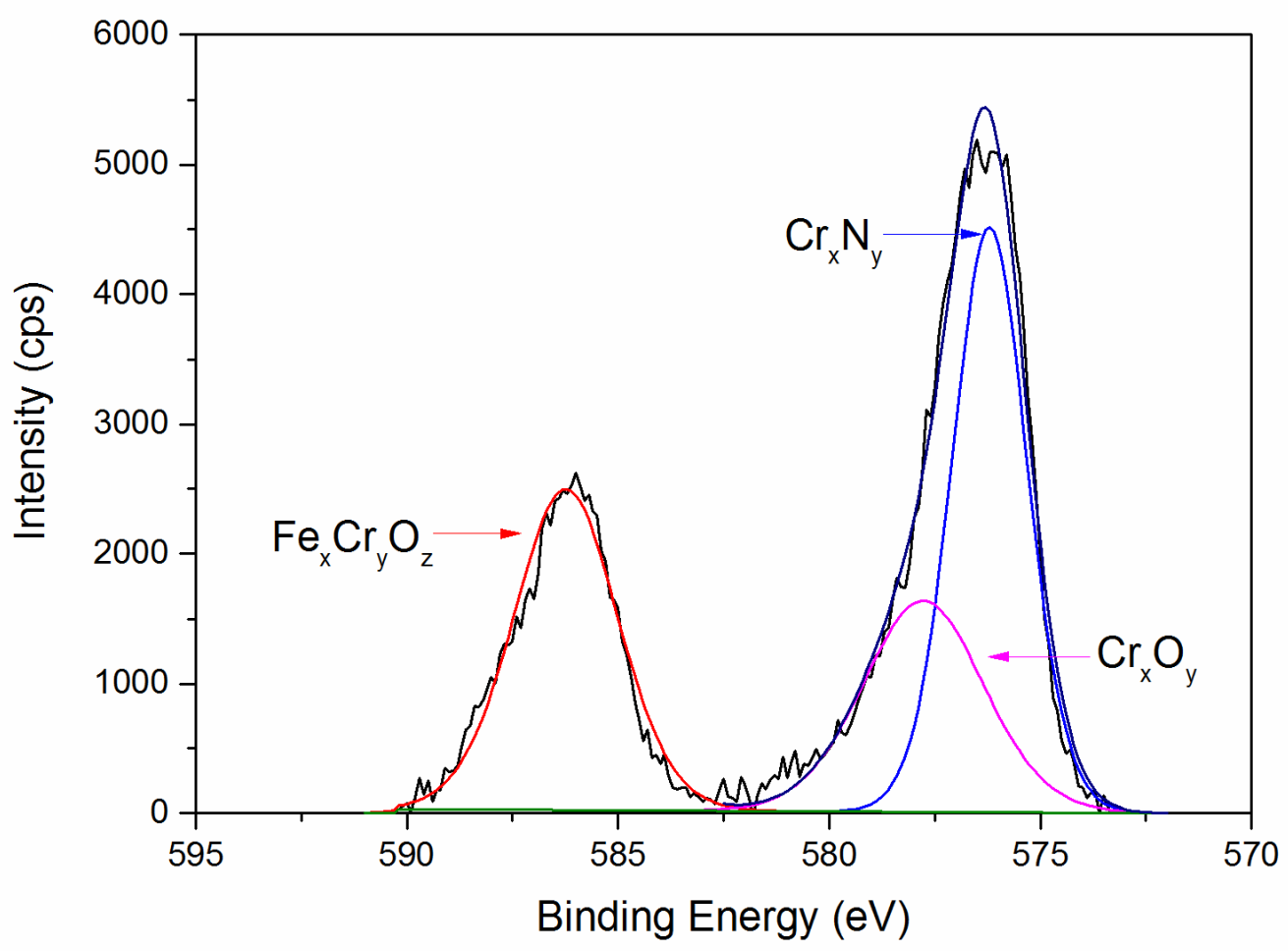

FIG 6a 


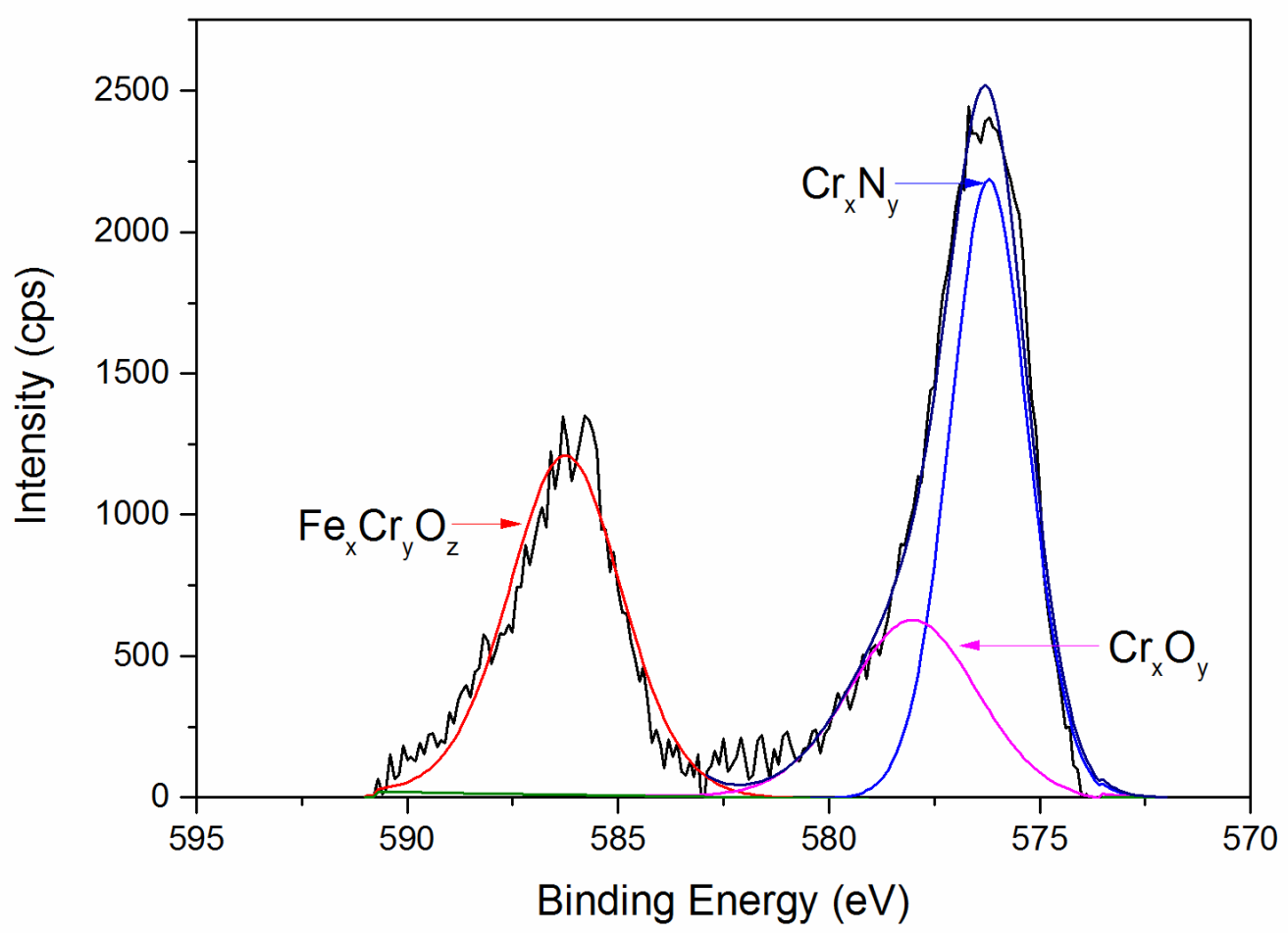

FIG 6b

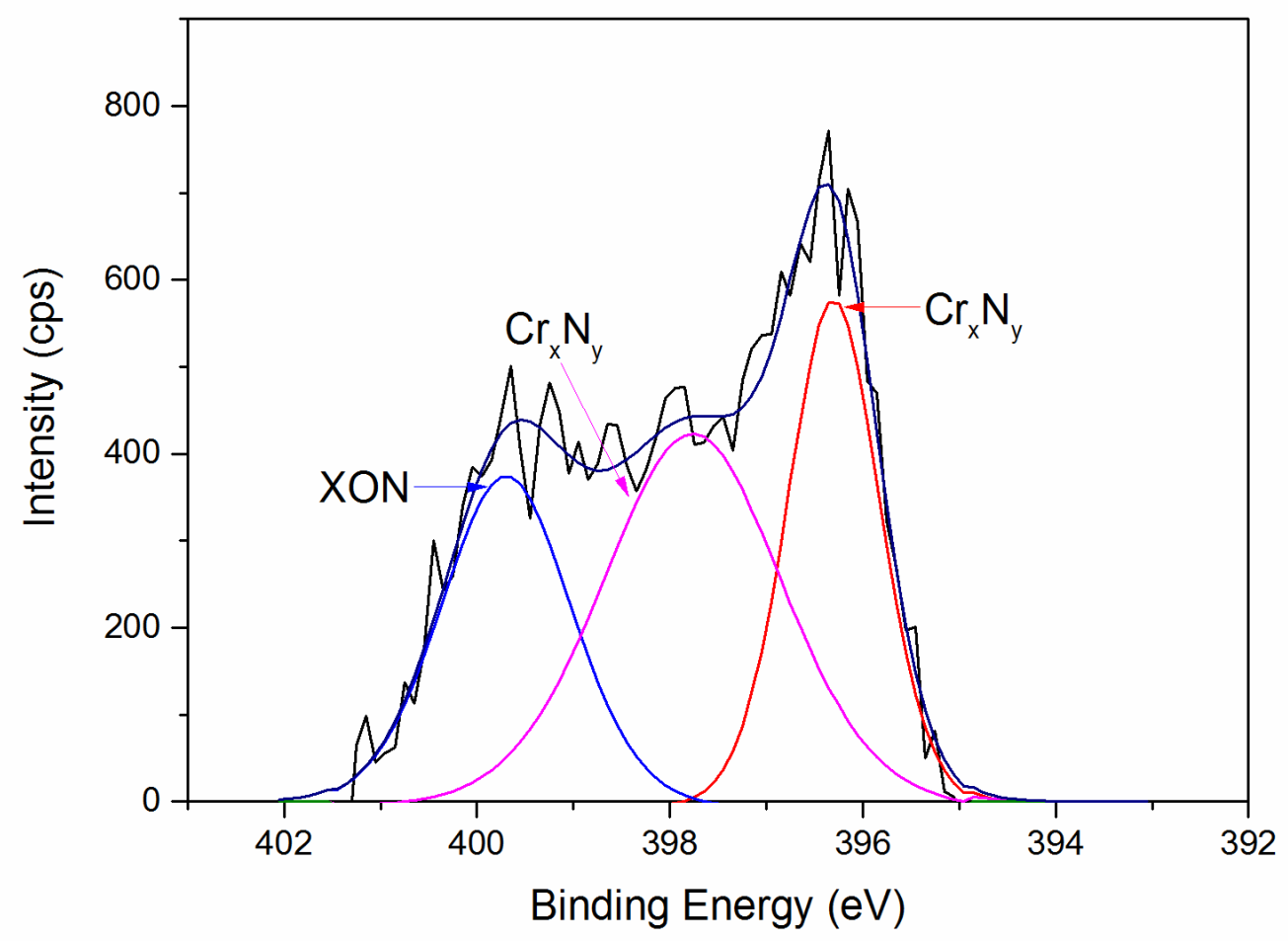

FIG 7a 


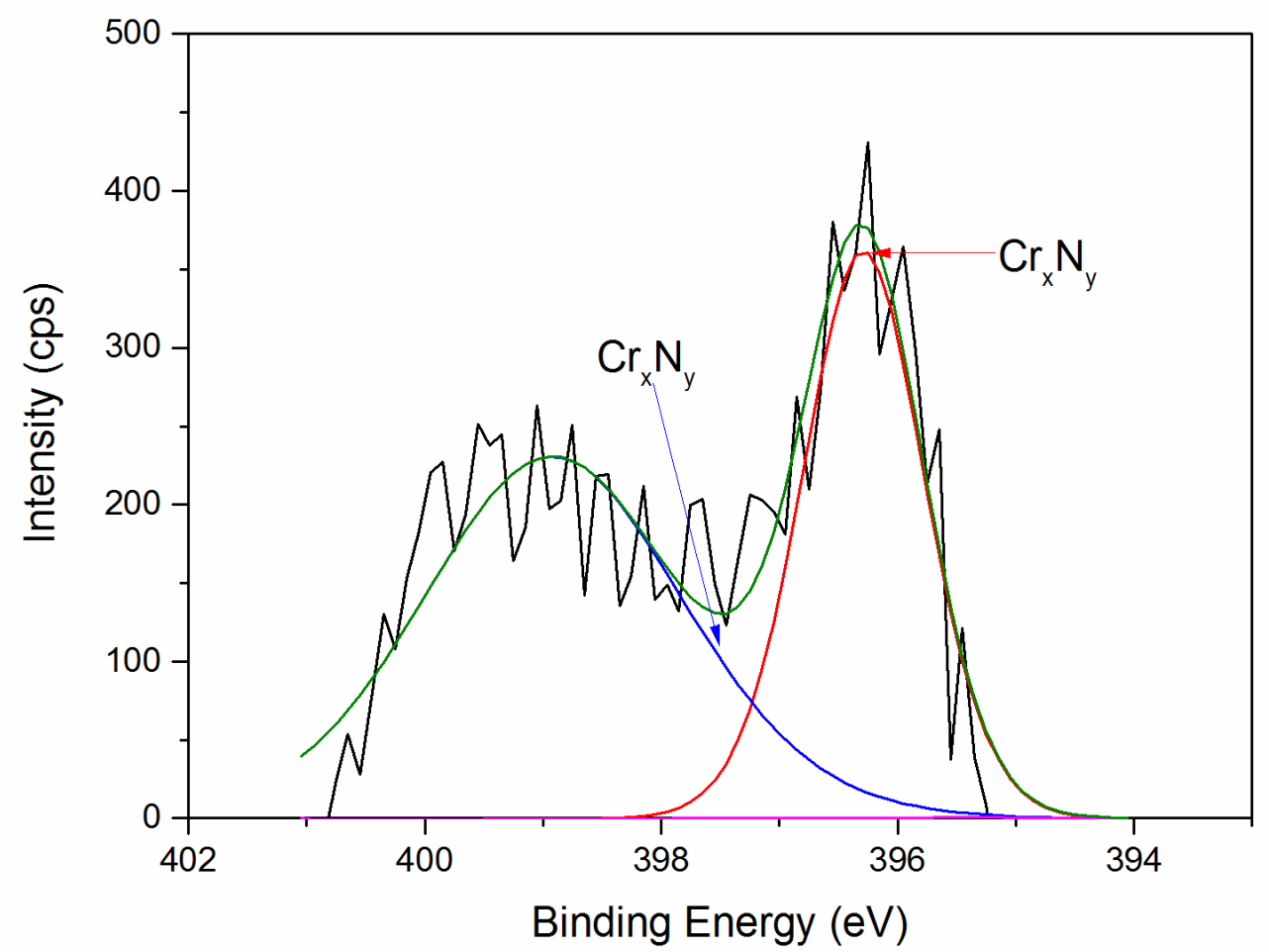

FIG 7b

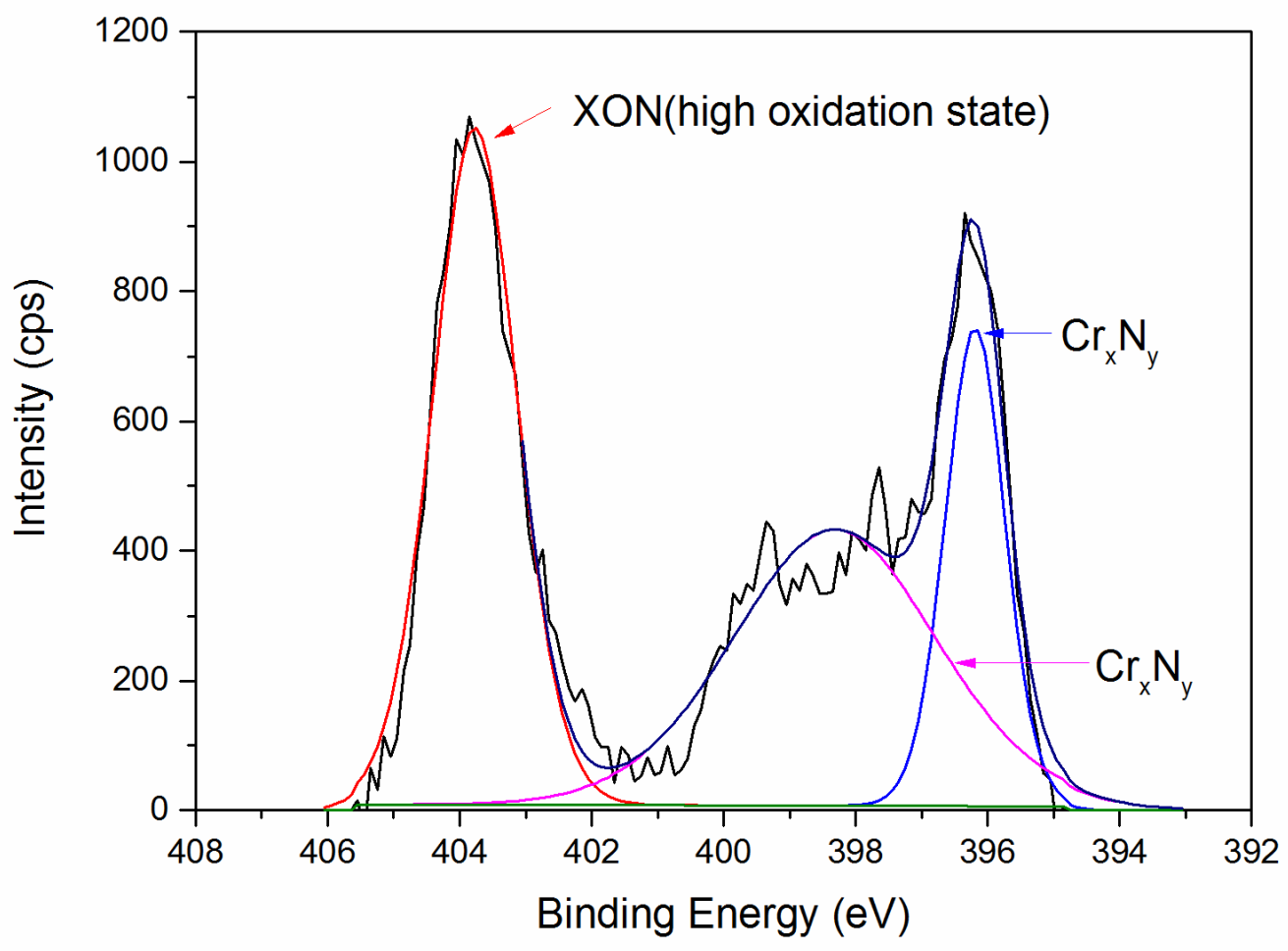

FIG 7c 


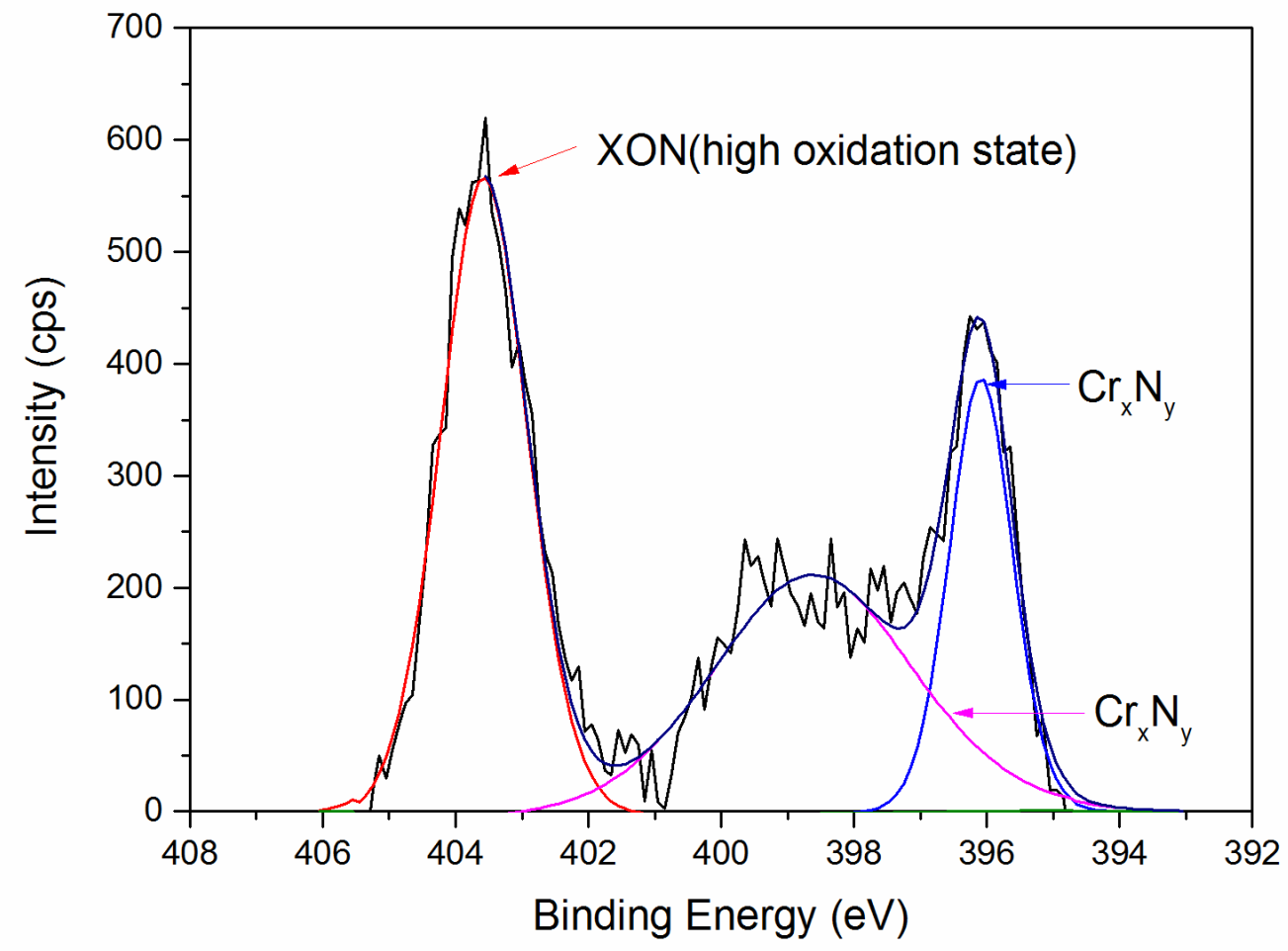

FIG 7d

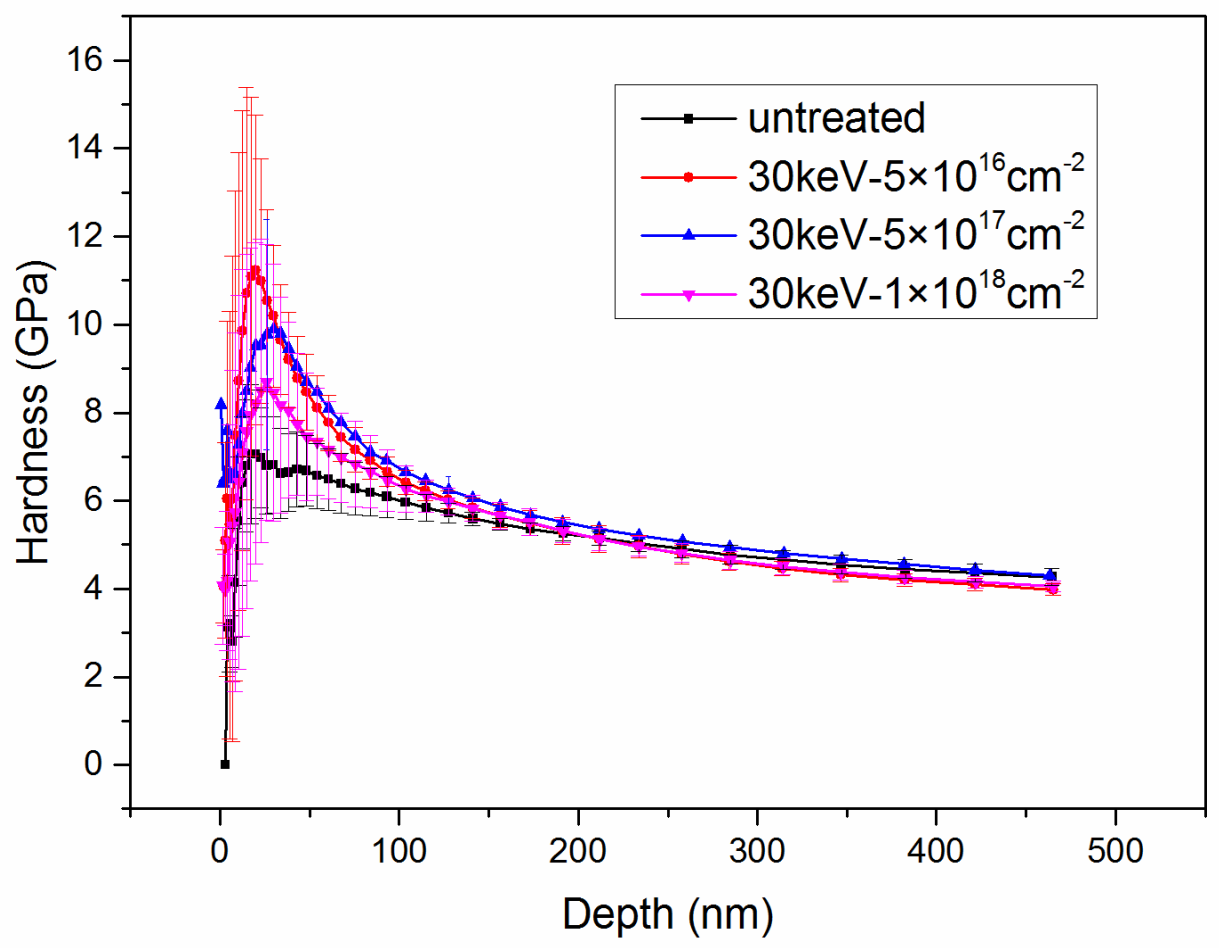

FIG 8a 


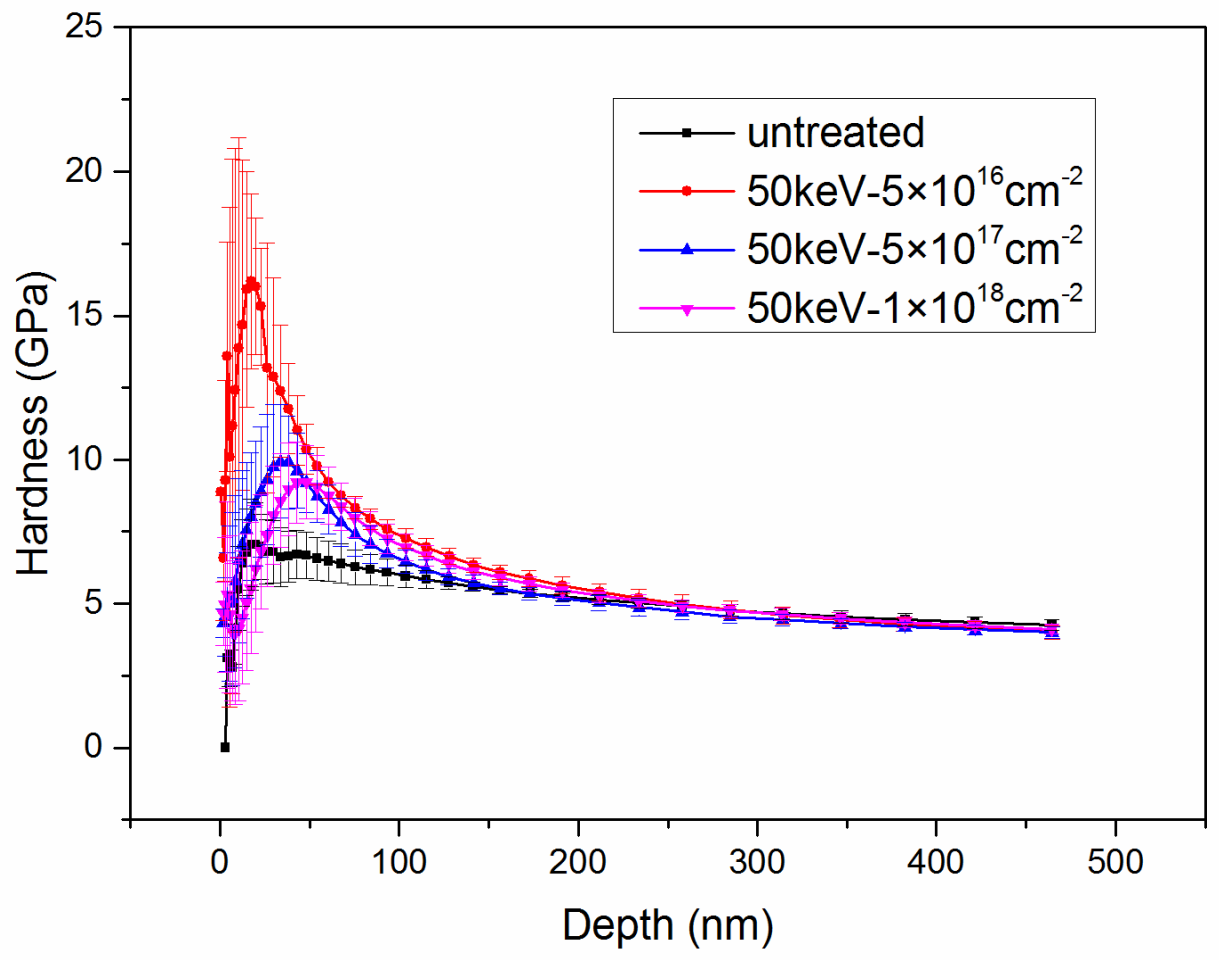

FIG $8 b$

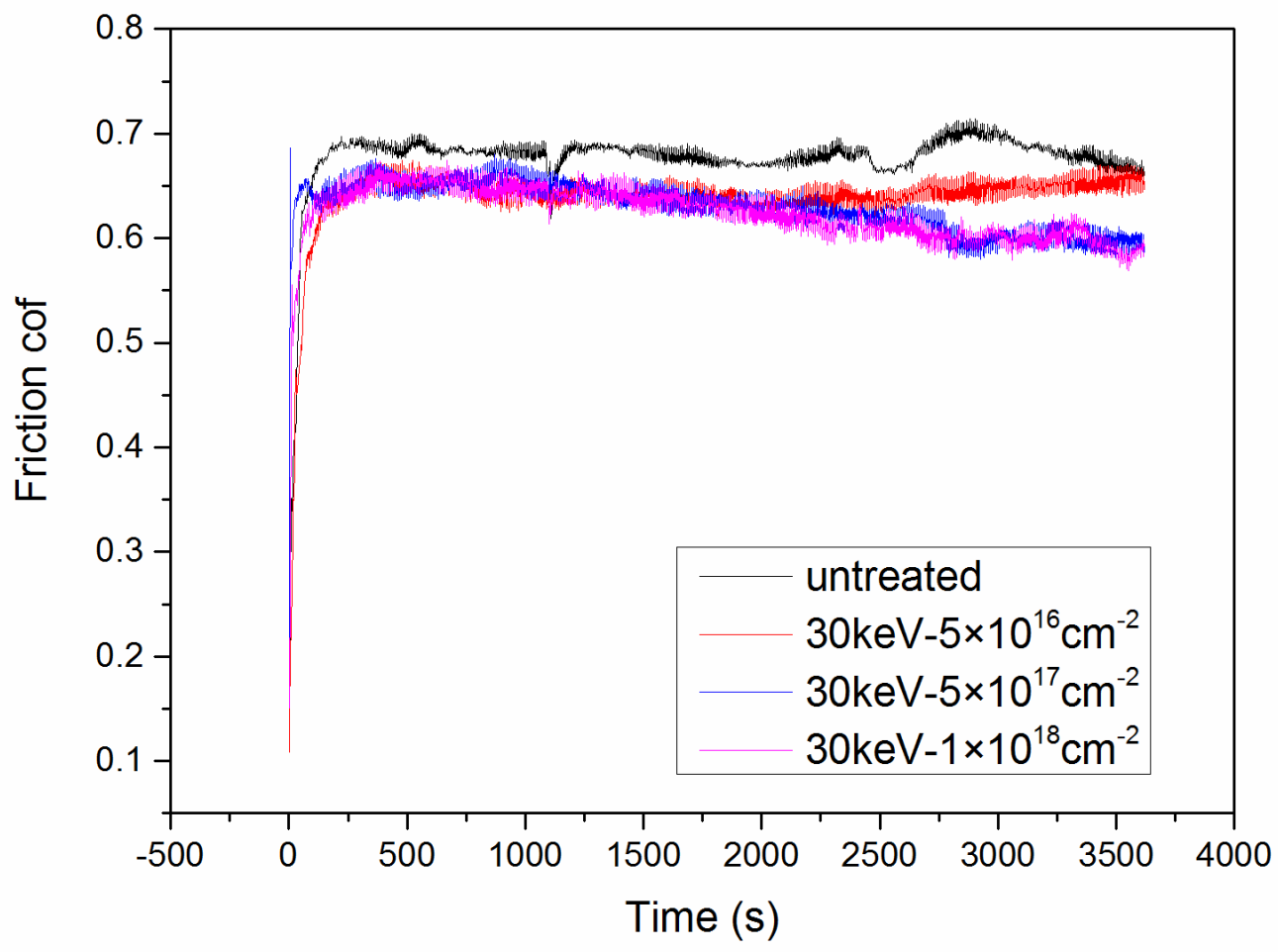

FIG 9a 


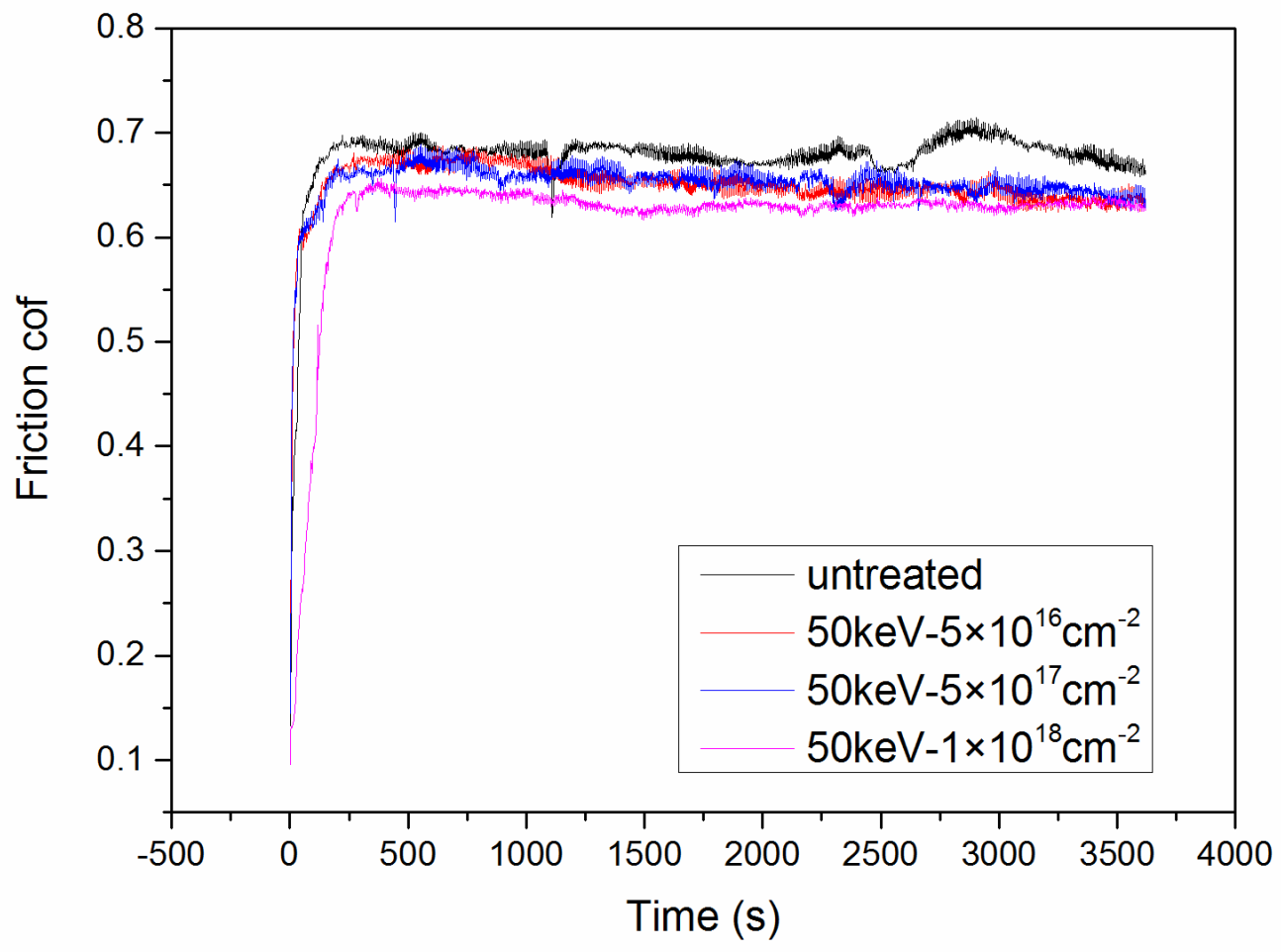

FIG 9b

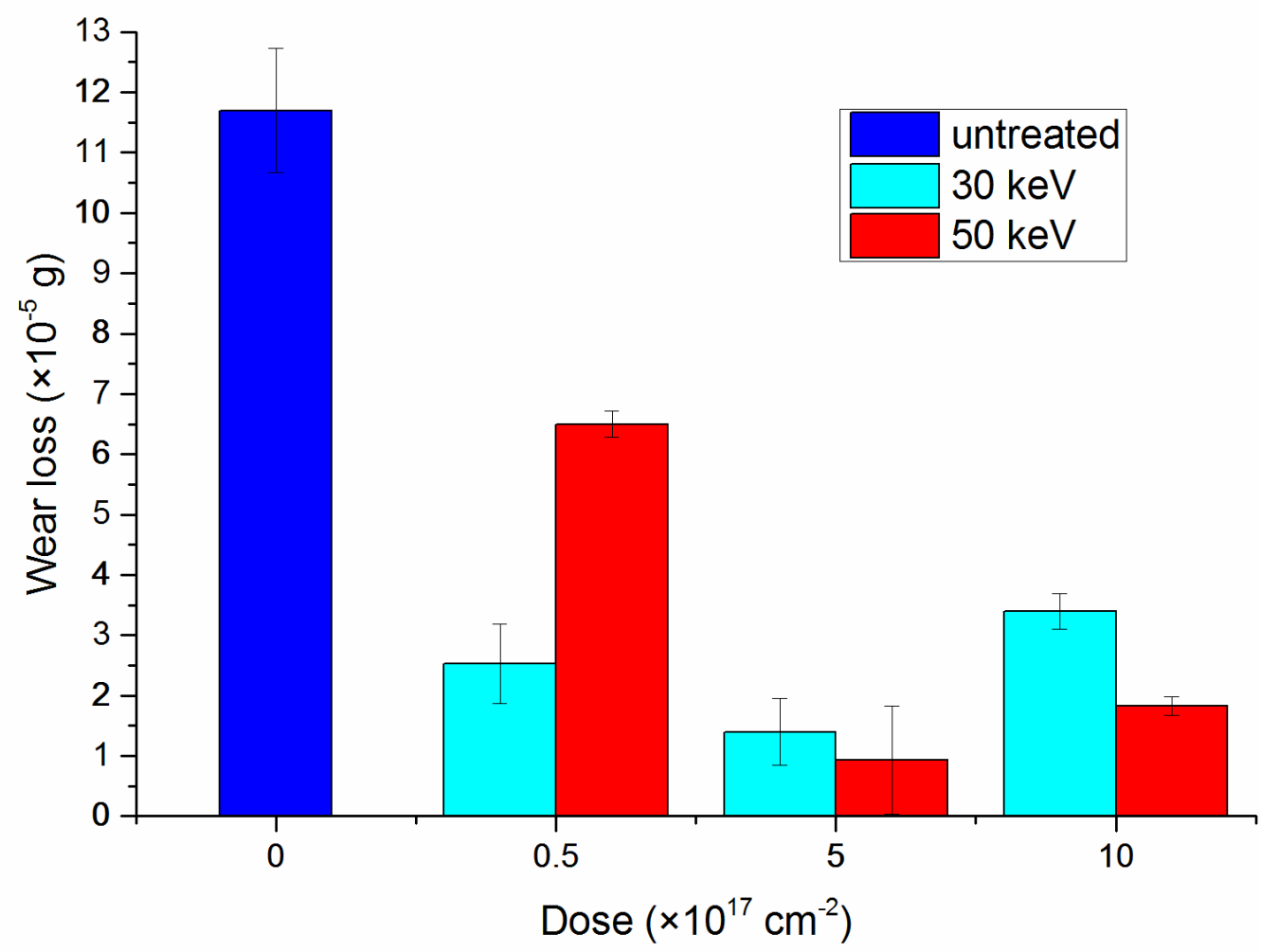

FIG 10 